Temp: $\# 42353$

NASA Technical Memorandum 83502

\title{
Correlation of Flight Effects on Centerline Velocity Decay for Cold-Flow Acoustically Excited Jets
}

Uwe H. von Glahn

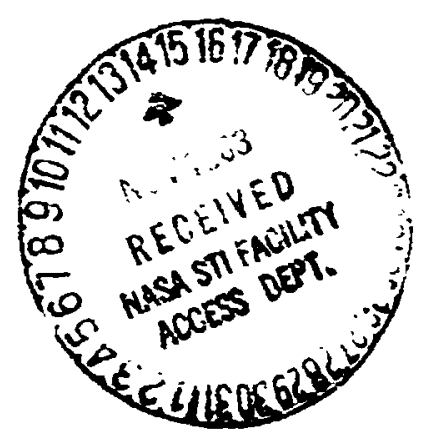

Lewis Research Center

Cleveland, Ohio
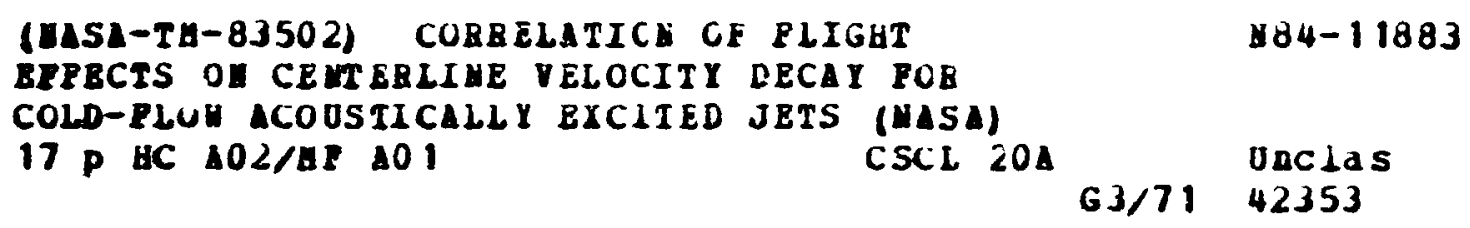

$\$ 84-11883$

Unclas

$63 / 7142353$

Prepared for the

One hundred sixth Meeting of the Acoustical Society of America San Eiego, California, November 7-11, 1983 


\title{
CORRELATION OF FLIGHT EFFECTS ON CENTERLINE VELOCITY DECAY
}

\author{
FOR COLD-FLOW ACOLSTICALLY EXCITED JETS
}

\author{
Iwe H. von Glahn \\ Nationa? Aeronautics and Space Administration \\ Lewis Research Center \\ Cleveland, Ohio $\mathbf{4 4 1 3 5}$
}

\begin{abstract}
Acoustic excitation can influence the larqe-scale sheur iayor structure of jet flow, thereby causing the jet centerline velocity to decay more rapidly. This phenomena has numerous practical applications, such as the reduction of jet/flap impingement velocity in order to reduce flap structural loads for under-the-wing STOL aircraft concepts. In the present paper, cold-flow centerline velocity decay data obtained with acoustic excitation of the jet exhaust flow are correlated with and without fliaht effects. Initially, static data are correlated in terms of a new acoustic parameter involving the threshold suund level needed to initiate acoustic excitaticn of the jet plume. It is shown that for a given flight speed, the same acoustic excitation parameter as tha. developed for the static condition is valid. Finally, an aerodynamic flight effects parameter is included to correlate the static and flight centerline velocity decay data with and : ithout acoustic excitation.
\end{abstract}

\section{INTRODUCTION}

Since the 1950 's, the literature has become increasingly replete with analyses and experiments aimed at determining and explaining the effect of exciting shear flows. The methods used to excite the flow have varied from spark sources and mechanical means to acoustics. The latter method was intensively studied in reference 1, under NASA Contract NAS3-21987, in order to obtain an understanding of the mechanism of subsonic broadband jet noise augmentation due to upstream tone-excitation. As part of this study, aerodynamic jet plume data concerned with changes of the centerline jet velocity decay were obtained with and without forward velocity. It is shown by the measured data that to ?-excitation of the iet plume reduces the core length and spreads the olume radiallv (fig. 1). Consequently, the local jet plume decav can be significantly increased (lower velocities) by excitina the jet plume. Such information is paramount for manv practical applications for plume decay alteration, including the reduction of jet/flap interaction for STOL aircraft. For example, if the iet impingenent velocity on a STOL deflected fiap system is reduced by tone-excitation the far-field noise level also is reduced. In addition, the local flap loads are also reduced by the lower impingement velocitv leading to lower flap structural weights.

The most comprehensive plume decay data subject to acoustic toneexcitation are report.ed in reference 1 . Included in this research are severa? subsonic jet Mach numbers, acoustic tone-excitation levels, and both static and flight (free jet simulation) conditions. All of the data were obtained with cold flow and a conical nozzle. The mechanism by which tone-excitation alters the flow structure, according to reference 1 , is by the phase-locking of the large-scale jet structure with the acoustic excitation signal. The result is an enhanced mixing of the jet stream with the surrounding medium by which the jet ccre is reduced and the jet spread is enhanced. 
In the present paper, the data included in reference 1 are analysed and correlated in terms of global aerodynamic and acoustic parameters. The correlation parameter developed accounts for the effects of jet exit Mach number, flight speed, and acoustic tone-excitation level.

\section{FACILITY}

The data were obtained in the turbulence facility described fully in reference 1. Briefly, the source section used for the acoustic experiments is centered around a 10-cm diameter duct and utilizes four e? 'ctro-acoustic 100 watt Altec drivers (fig. 2). Each driver is enclosed in a pressure vessel to equalize the pressure across the driver diaphragm. The source section is located in a constant $10-\mathrm{cm}$ diameter pipe section, six meters upstream of the nozzle exit plane. The most critical feature of the source section is the requirement to generate modes in isolation. To achieve this, the input signal for each driver is passed through individual power amplifiers with provision for input (amp!itude and phase) control in order to ensure generation of the plane wave $(0,0)$ mode, or the helical $(1,0)$ mode in isolation.

\section{DATA ANALYSIS}

Although both $(0,0)$ and $(1,0)$ modes were studied in reference 1 , the effect on the jet plume decav were much greater for the plane wave $(0,0)$ mode than for the helical $(1,0)$ mode. Thus, only the $(0,0)$ mode data are included herein. Furthermore, it was determined that an excitation Strouhal number of 0.5 resulted in near maximum acoustic tone-excitation levels and concurrently most rapid centerline jet velocity decay. Consequently, only data at this excitation Strouhai number is included in the present analysis.

\section{RESIJLTS}

It is well documented in the literature that jet excitation under static operating conditions can result in the plume effects noted previously for figure 1 . In the following sections, the static centerline jet velocity decay data are first correlated with and without excitation. The fliqht centerline jet velocity decay data are then correlated with and without excitation and compared with the static data.

\section{Static Operating Conditions}

Without excitation. - The centerline jet velocity decay of reference 1 is shown in figure 3 correlated in terms of the static velocity ratio, $U / U_{j}$, as a function of the relationships developed in references 2 and 3 . These are given by:

$$
\frac{U}{U_{j}} \sim \frac{x}{D \sqrt{1+M_{j}}}\left(\frac{t_{i}}{t_{0}}\right)^{0.25}
$$

while the range of jet Mach numbers is limited for the data in figure 3 , it is shown in reference 3 that equation (1) is applicable over a wide range of jet Mach numbers, including supersonic flow. It should be noted that the curve shown in figure 3 is falred through the present data but is similar to that 


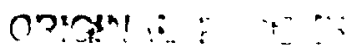

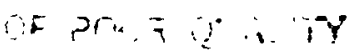

given in reference 3; being displaced by a factor of about 1.04 to the right on the abscissa from the general curve given in the reference 3 .

With excitation. - Typical excited flow centerline jet velocity decay results from reference 1 are shown in figure 4 for a jet Mach number of 0.58 . The acoustic tone-excitation levels at the nozzle exit associated with these data range from 128 to $14 i \mathrm{~dB}$. Also shown in the figure, for comparison, is the static decay curve from figure 3. Increasingly more rapid decreases in $\left(U / U_{j}\right)$ with $(X / D)$ occur with increases in the excitation level. Similar results were obtained with a $M_{j}$ of 0.78 .

In reference 4 , it was determineo that a minimum excitation or threshold acoustic level exists below which the plume flow is not oxcited. This threshold acoustic excitation level, specified at the nozzle exhaust piane, is a function of the jet Mach number and the Strouhal excitation number, $S_{e}$. From figures 39 and 40 in reference 4 , the acoustic excitation threshold levels, $L_{T}$, for the jet exit Mach numbers of 0.58 and 0.78 were determined to be 124 and $129.5 \mathrm{~dB}$, respectively at a Strouhâl excitation number, $\mathrm{S}_{e}$, of 0.5 .

In order to correlate the velocity decay data associated with various acoustic tone-excitation levels, $L$, the axial distance/temperature parameter shown by the abscissa in figure 3 must include an acoustic excitation parameter, designaied herein as $L_{e}$. An evaluation of several mathematical expressions for such a parameter indicated that one in the form of $[1+f(L)]$ appeared suitable. In figure 5 is shown the variation of $\left[\mathrm{Le}_{e}-1\right]$ as a function of the measured and threshold acoustic tone-excitation levels. A straight ? ine through the data yields the following empirical parameter:

$$
L_{e}=1+2\left(\frac{L-L_{T}}{L_{T}}\right)
$$

which is considered to be vaiid for $\left(L-L_{T}\right) \geq 0$.

In figure 6 are shown the correlated static centerline jet velocity decay data with excited flow. Also shown for comparison is the curve from the decay data without excitation (fig. 3). It is apparent that equations (1) and (2) correlate the decay data with and without acoustic tone-excitation extremely well.

\section{Flight Operating Conditions}

In considering flight effects on the jet plume velucity decay, the $\left(1 / U_{j}\right)$ ordinate in the previous figures is conventionally modified to include the flight velocity, $U_{0}$, leading to a velocity decay parameter given by $\left(U-U_{0}\right) /\left(U_{j}-U_{0}\right)$. This parameter will be used hereinafter for all plats involving flignt speed.

Without Excitation. - In figure 7, the typical effect of flight speed on the centerline jet velocity decay is shown. Also shown in the figure for comparison is the static curve from figure 3 . The velocity decay curve is seen to be shifted to the right with increasing flight speeds.

For the data in reference 1 , the effect of flight speed on the centerline jet velocity decay was correlated by the following empirically determined parameter:

$$
U_{F}=\left[1+\frac{0.115 \sqrt{\pi_{0} / U_{j}}}{\left(M_{j}\right)^{3}}\right]^{-1}
$$


In figure 8 are shown the correlated centerline jet velocity decay data for the several flight speeds included in reference 1. Again shown for comparison is the static curve from equation (1). Good agreement for the static condition and all flight speeds was obtained by the use of equation (3).

With excitation. - Before evaluating the applicability of the unexcited flow flight speed parameter (eq. (3)) to excited flow, it is necessary to determine if equation (2) is applicable 'o excited flow in the presence of flight speed.

In figure 9 , is shown the centerline jet velocity decay data for constant flight speeds and several acoustic tone-excitation levels, including no acoustic excitation. It is evident that equation (2), developed for excited jet flow under static conditions applies equally well to flight conditions.

The typical effect of flight speed on the excited centerline jet velocity decay is shown in figure 10. Also shown for comparison are unexcited decay curves at the same flight speed. In general, the excited plume decay data exhibit the same trends with flight speed as the unexcited plume data. In figure 11 , the excited plume data from reference 1 are shown correlated for the effects of acoustic excitation level and flight speed. Again, the static decay curve from figure 3 is used as a reference. In general, the equations developed herein correlated the excited plume velocity decay with and without flight speed in an acceptable manner.

\section{CONCLUDING REMARKS}

It har been shown in the present work that in a global sense, the centerline jet velocity decay with and without acoustic tone-excitation and for both static and flight conditions can be correlated by the use of excitation and flight parameters. However, it is apparent that in the jet core region $(x / 0<5)$ the shape of the velocity decay curve is different for excited flow than for unexcited flow. The difference is illustrated in figure 12. Shown in the figure ere unexcited, excited and correlated excited centerline jet velocity decay curves. The present correlation equations do not account for the crosshatched resion shown in the figure. In this region, the reduced local velocity decay amounts to less than 4 percentage points for the data in reference 1. However, when considering some other means of exciting the jet plume, such as the use of a whistler nozzle (ref. 5), the local reduced decay in the core region can amount to as much as 15 percentage points. As in the case of the preserit data, the local reduced decay with a Whistler nozzle is a function of jet exit Mach number, decreasing (less local velocity reduction) with increasing $M_{j}$ values. However, it should be pointed out also that exciting the jet plume with a mechanical rotating disk (ref. 6) or a elliptical focusing radiator (ref. 7 ) does not appear to cause a reduced local velocity decay in the core region. Rather, the excited jet velocity decay curve has the same shape as the unexcited jet velocity decay curve and is merely shifted to lower values of the axial distance parameter. Furthermore, limited data in reference 1 indicates that the reduced local velocity decay in the core region tends to disappear with increasing flight speed. The available data are too limited to justify correlation of the reduced velocity core region at this time.

It is apparent from this discussion that much fundamental research needs yet to be done, particularly in the core region, in order to understand the jet flow phenomena associated with excited jets in both static and flight conditions. Finally, the effect of elevated plume static temperatures on 
the excited velocity decay characteristics must be determined in order to assess the benefits derivable from acousticaliy excited jets for piractical applications.

\section{CONCLUSIONS}

From the present global analys is concerned with the centerline velocity decay of unexcited and excited jet plumes with and without forward velocity, the following conclusions can be made for the data included herein:

1. A correlation equation developed to correlate static acoustic toneexcited jet velocity decay also is applicable to that obtained in flight.

2. A correlat: in equation developed to correlate unexcited jet velocity decay in flight also correlates acoustic tone-excited jet velocity decay on the same curve.

3. Significantly more research needs to be coriducted to understand local velocity decay characteristics associated with excited jets, particularly in the core region with higher levels of acoustic excitation and at elevated plume static temperatures.

\section{SYMBOLS}

$D$
$L$
$L_{e}$
$L_{T}$
$M_{j}$
$S_{e}$
$t_{j}$
$t_{0}$
$U$
$U_{F}$
$U_{j}$
$U_{0}$
$X$

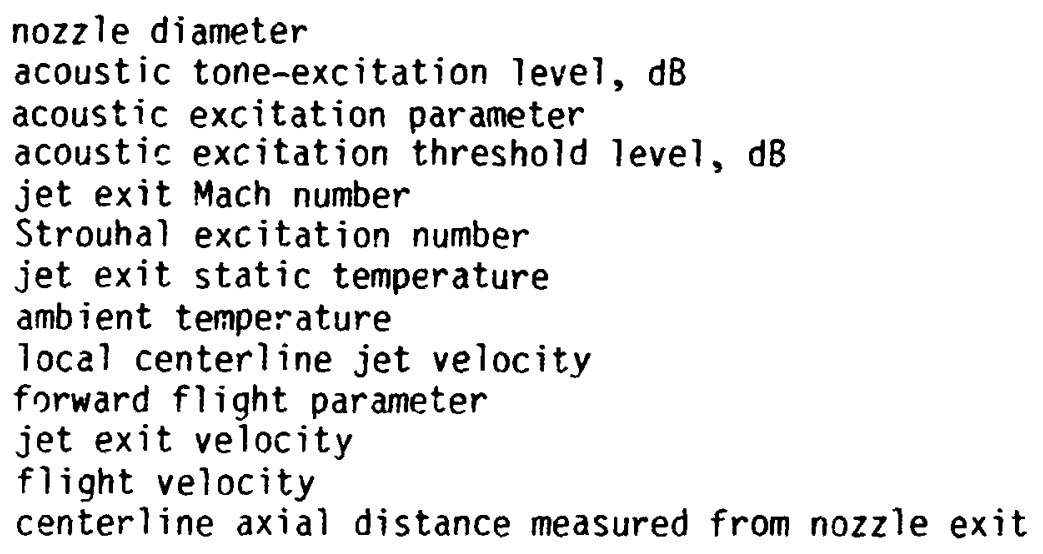

\section{REFERENCES}

1. K. K. Ahuja, J. Lepicovsky, C. K. W. Tam, P. J. Morris, and R. H. Burrin, "Torie-Excited Jet: Theory and Experiments" NASA CR-3538 (Nov. 1982).

2. D. E. Groesbeck, R. G. Huff, and U. H. von Glahn, "Comparisen of Jet Mach Number Decay Data with a Correlation and Jet Spreading Contours for a Large Variety of Nozzles," NASA TN D-8423 (June 1977).

3. li. von Glahn, "On Some Flow Characteristics of Conventional and Excited Jets," NASA TM-83503 (Jan. 1984).

4. C. J. Moore, "The Role of Shear Layer Instability Waves in Jet Exhaust Noise," J. Fluid Mech. 80 (2), 321-367 (1977).

5. M. A. Z. Hasan and A. K. M. F. Hussain, "The Self-Excited Axisymmetric Jet," J. Fluid Mech. 115, 59-89 (1982).

6. L. A. Vulis, "Turbulent Mixing of Free Gas Jets," Fluid Mech. Sov. Res. i (3), $0-135$ (1972).

7. Yu Ya Borisov and N. M. Gynkina, "Acoustic Excitation of High-Velocity Jets," Sov. Phys. Acoust. (Engl. Trans1.) 21 (3), 230-233 (1975). 


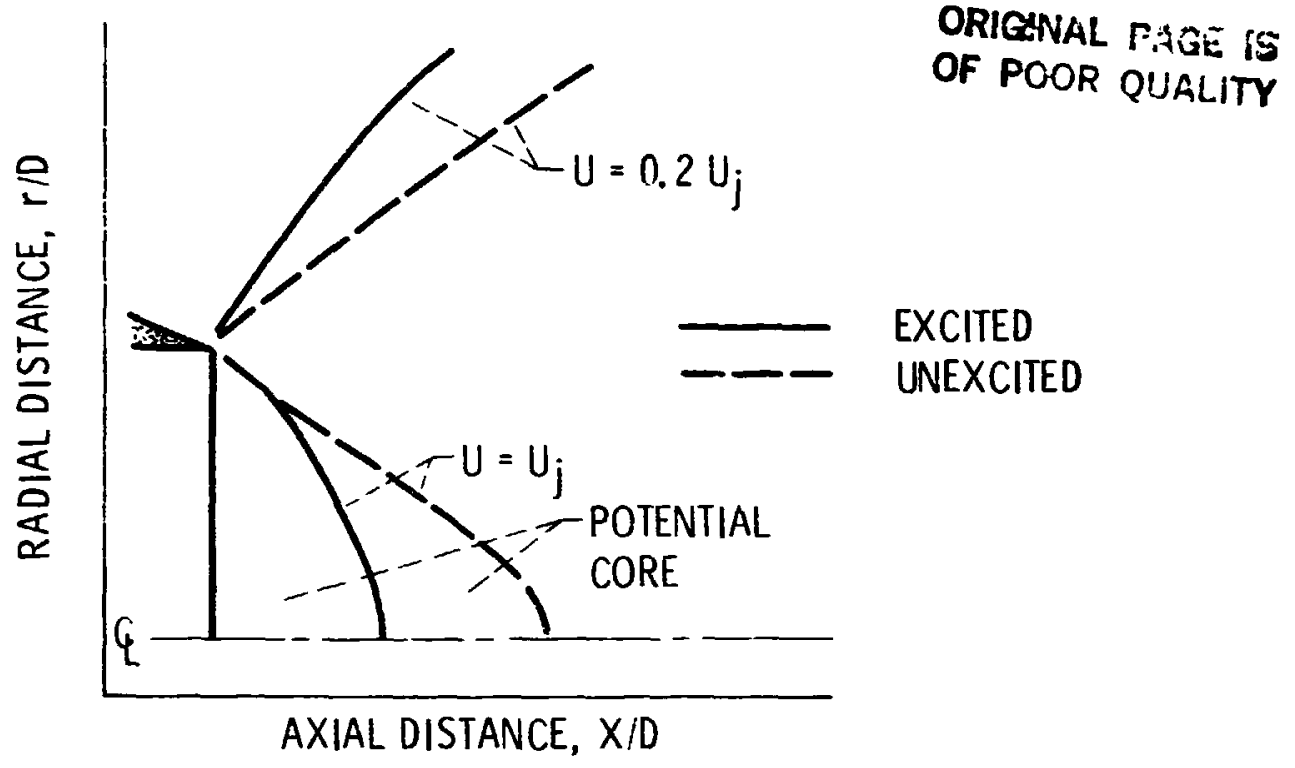

Figure 1. - Schematic sketch of acoustic tone-excitation effects on jet velocity decay.

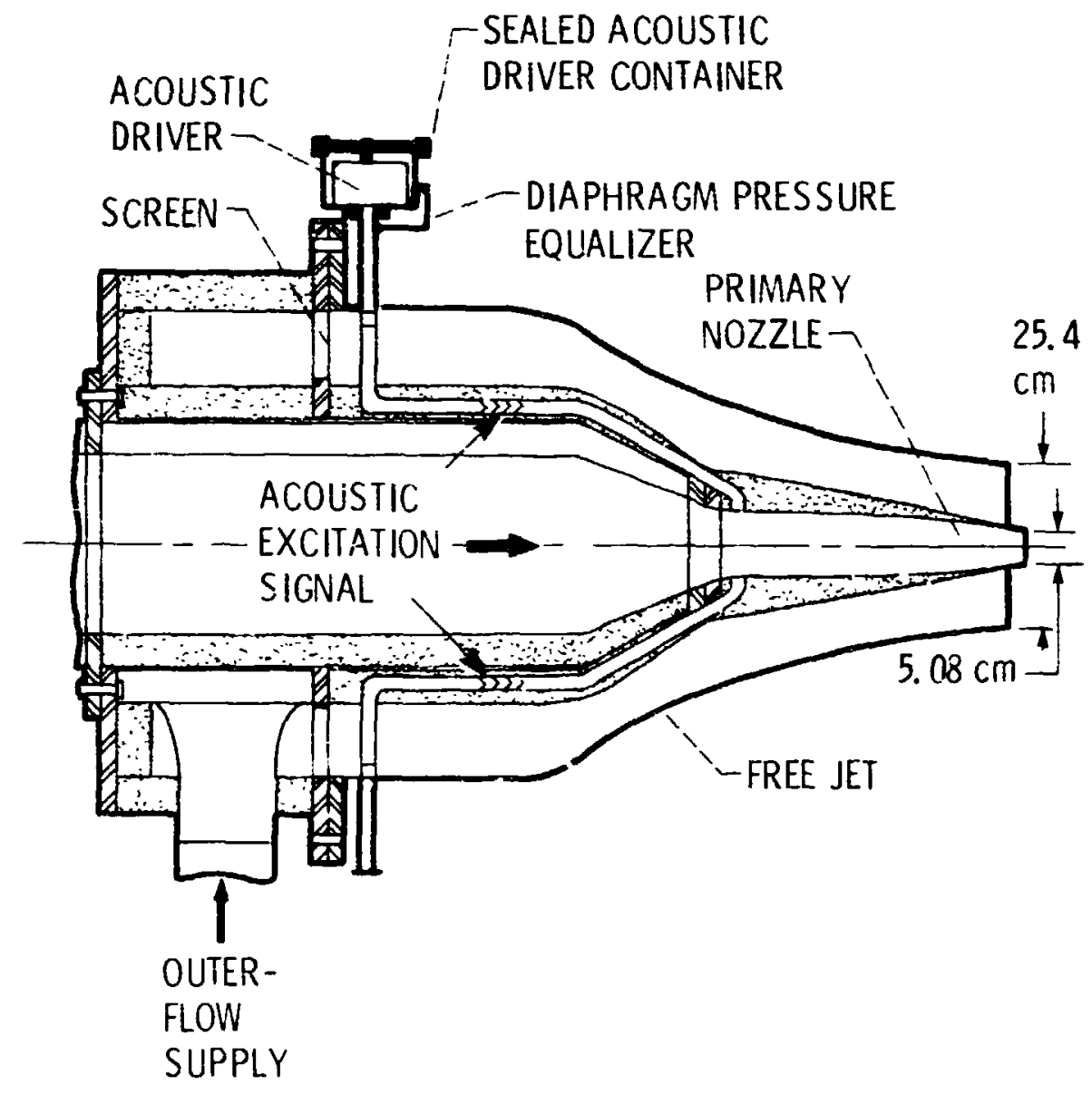

Figure 2. - Turbulence facility (ref. 1). 
Ofinim:-:-

OF PCOR CiJintis

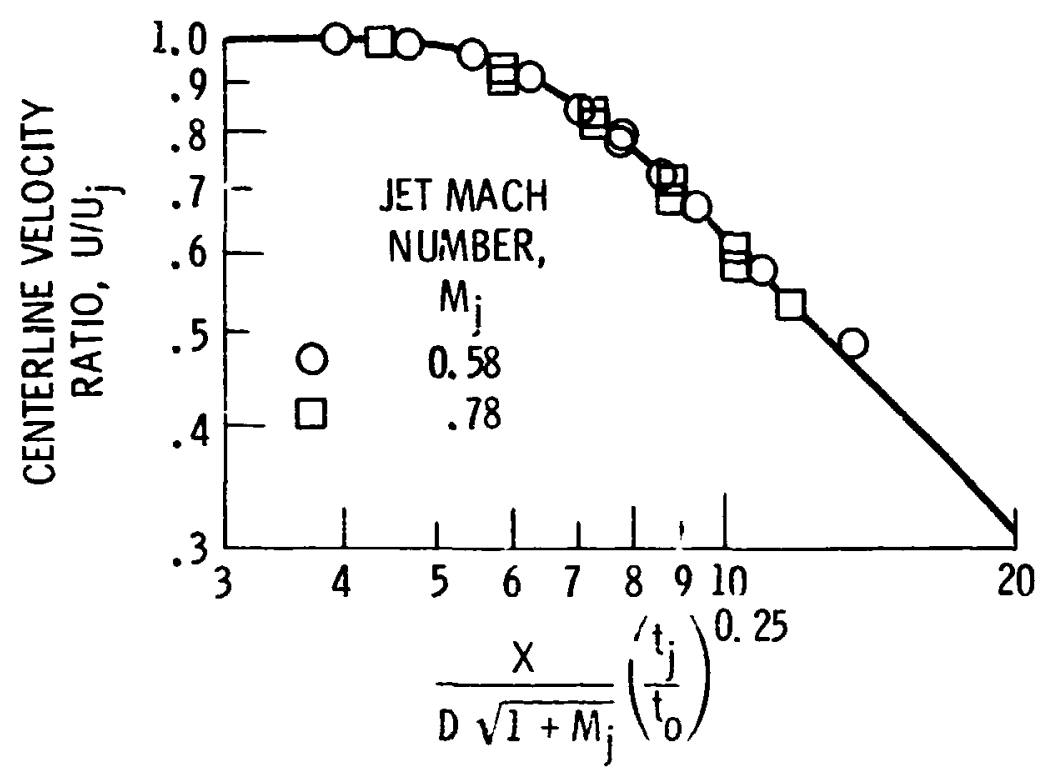

Figure 3. - Centerline jet velocity decay for static, unexcited flow concitions. Reference I ciata.

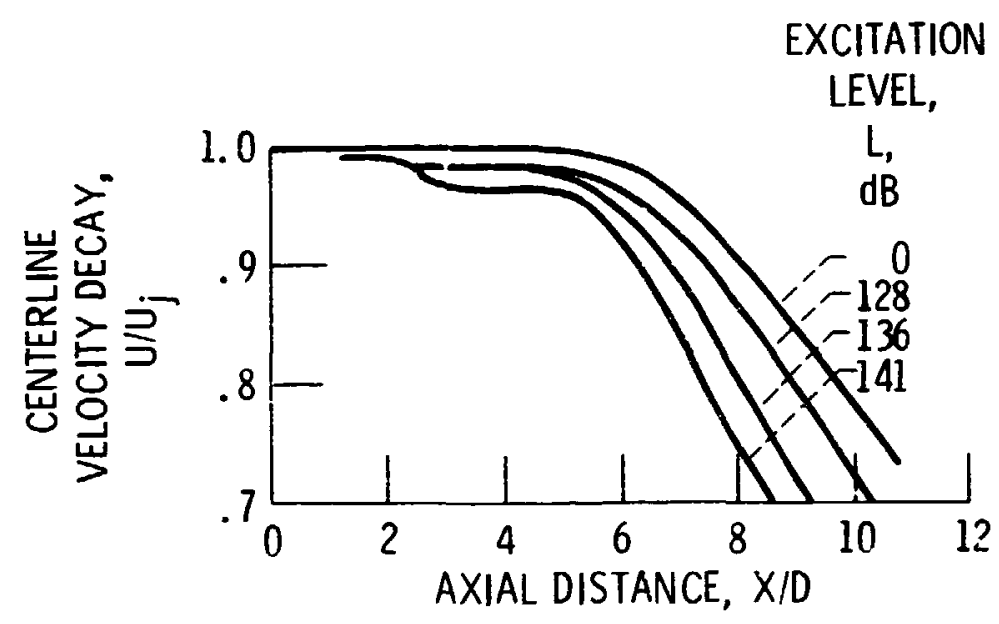

Figure 4. - Typical effect of tone-excitation on centerline jet plume velocity decay. $M_{j}, 0.58$; ref. 1 . 


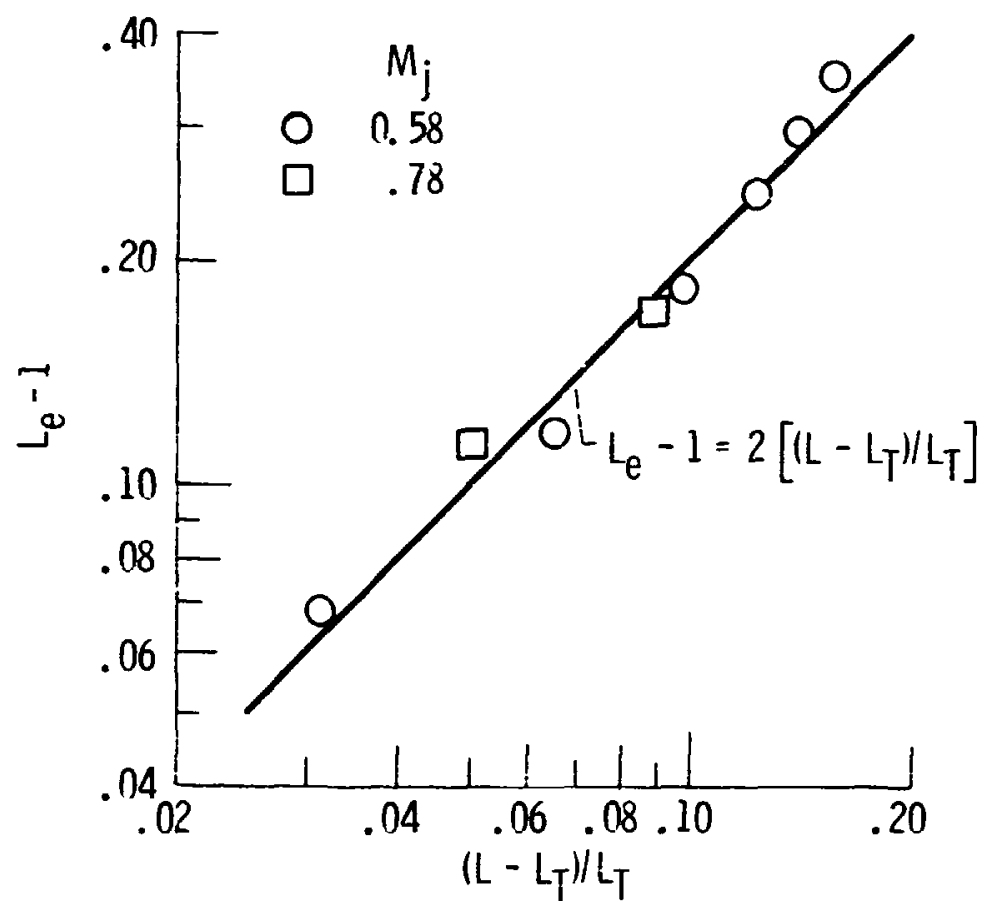

Figure 5. - Correlation of acoustic excitation parameter with acoustic tone-excitation level. 


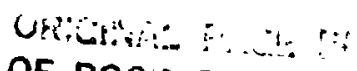

OF POOK QUALITY

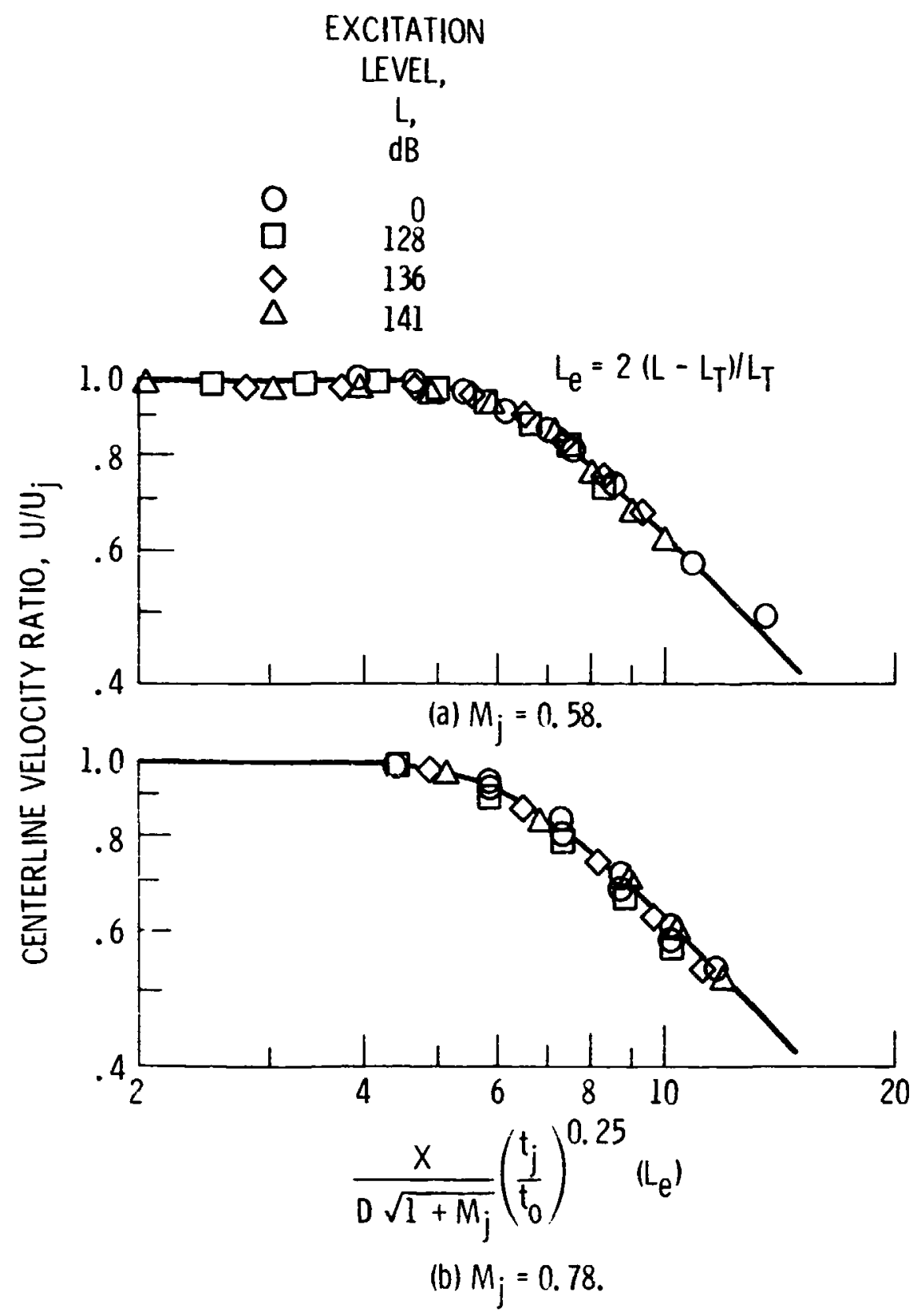

Figure 6. - Correlated centerline jet velocity decay for static flow conditions, with and without excitation. 


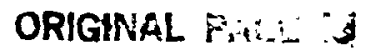 \\ OF POOR QUA:ITY}

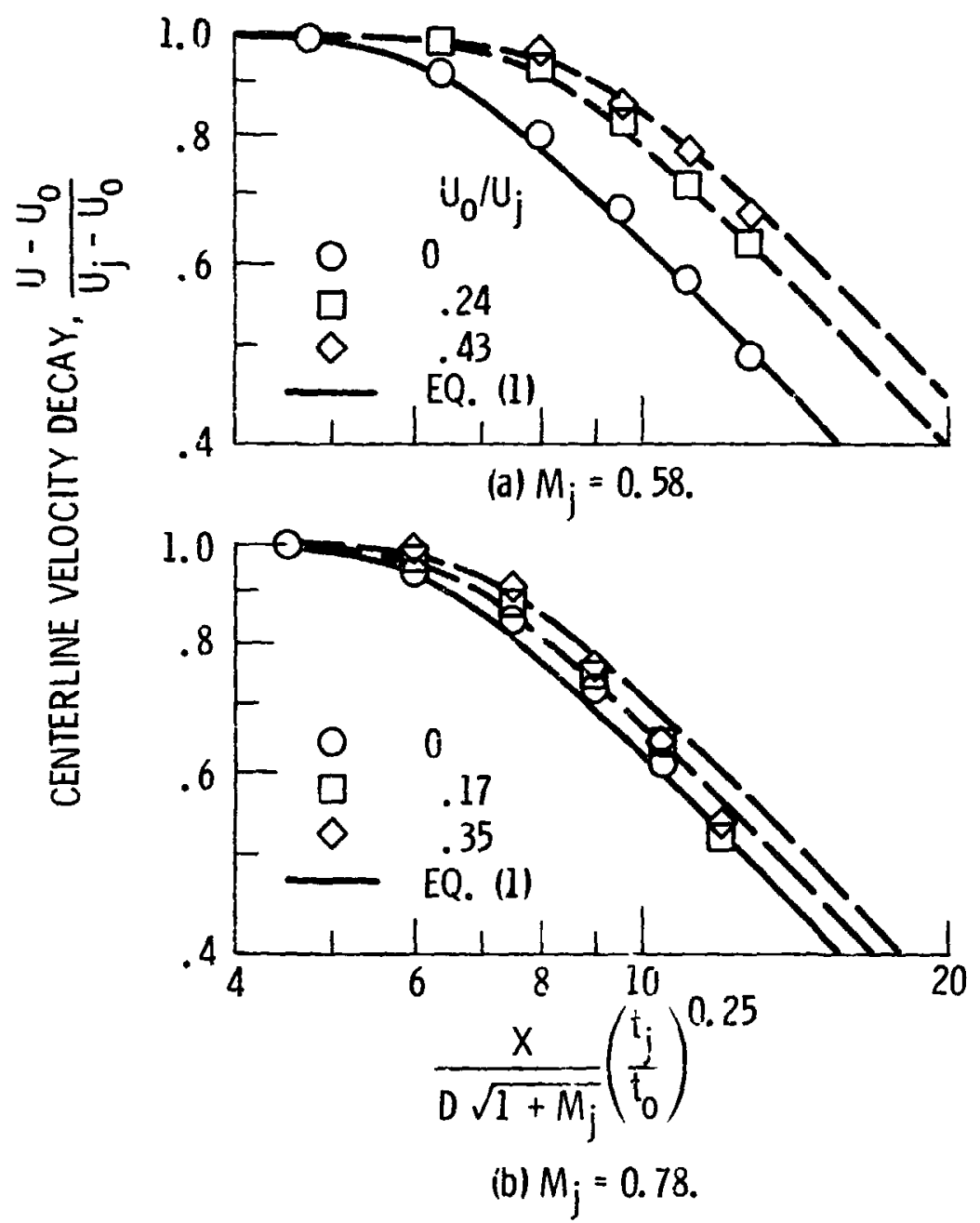

Figure 7. - Flight effect on unexcited centerline jet velocity decay. 
UHimist.

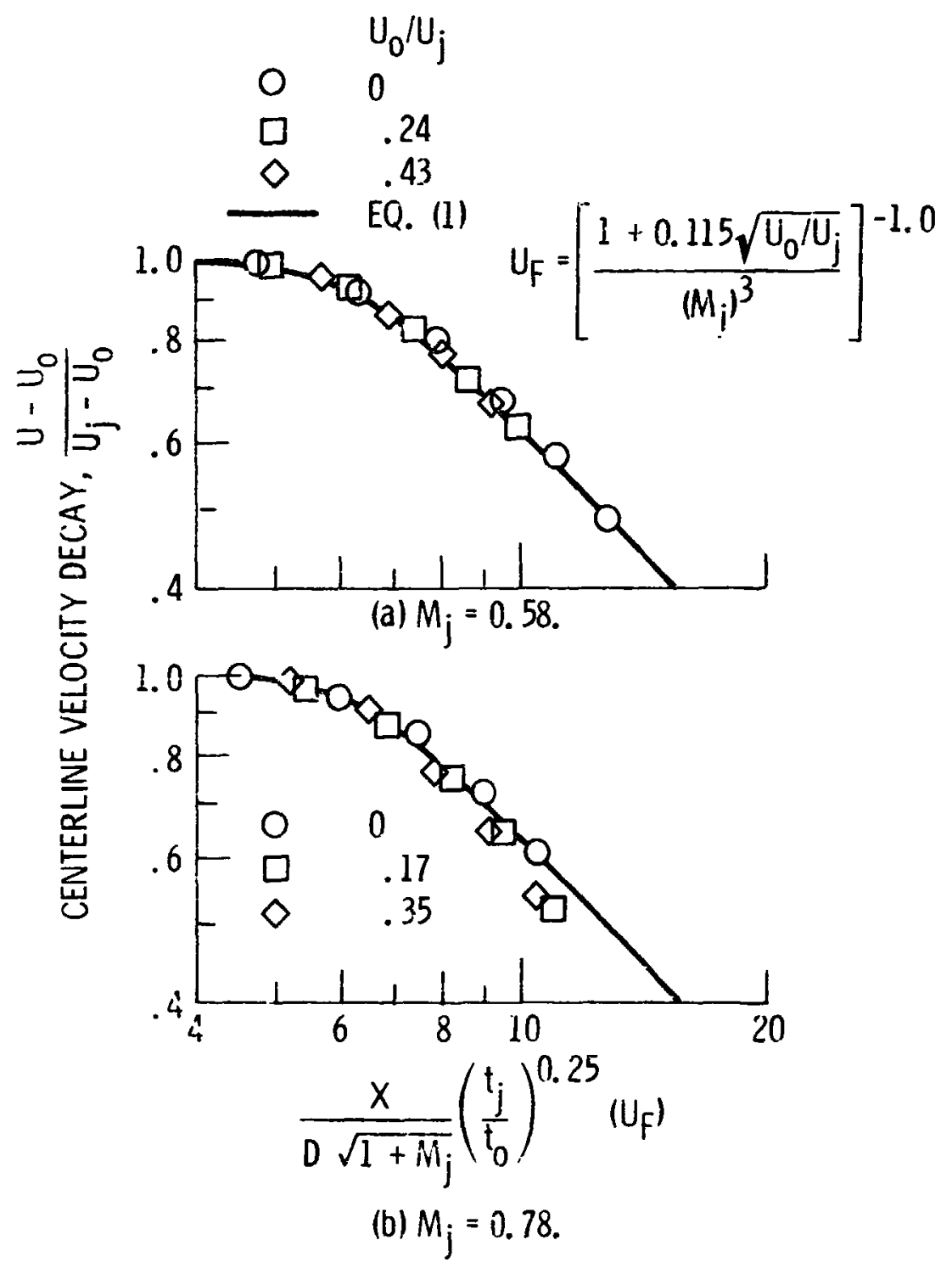

Figure 8. - Flight effect correlation of unexcited centerline jet velocity decay. 


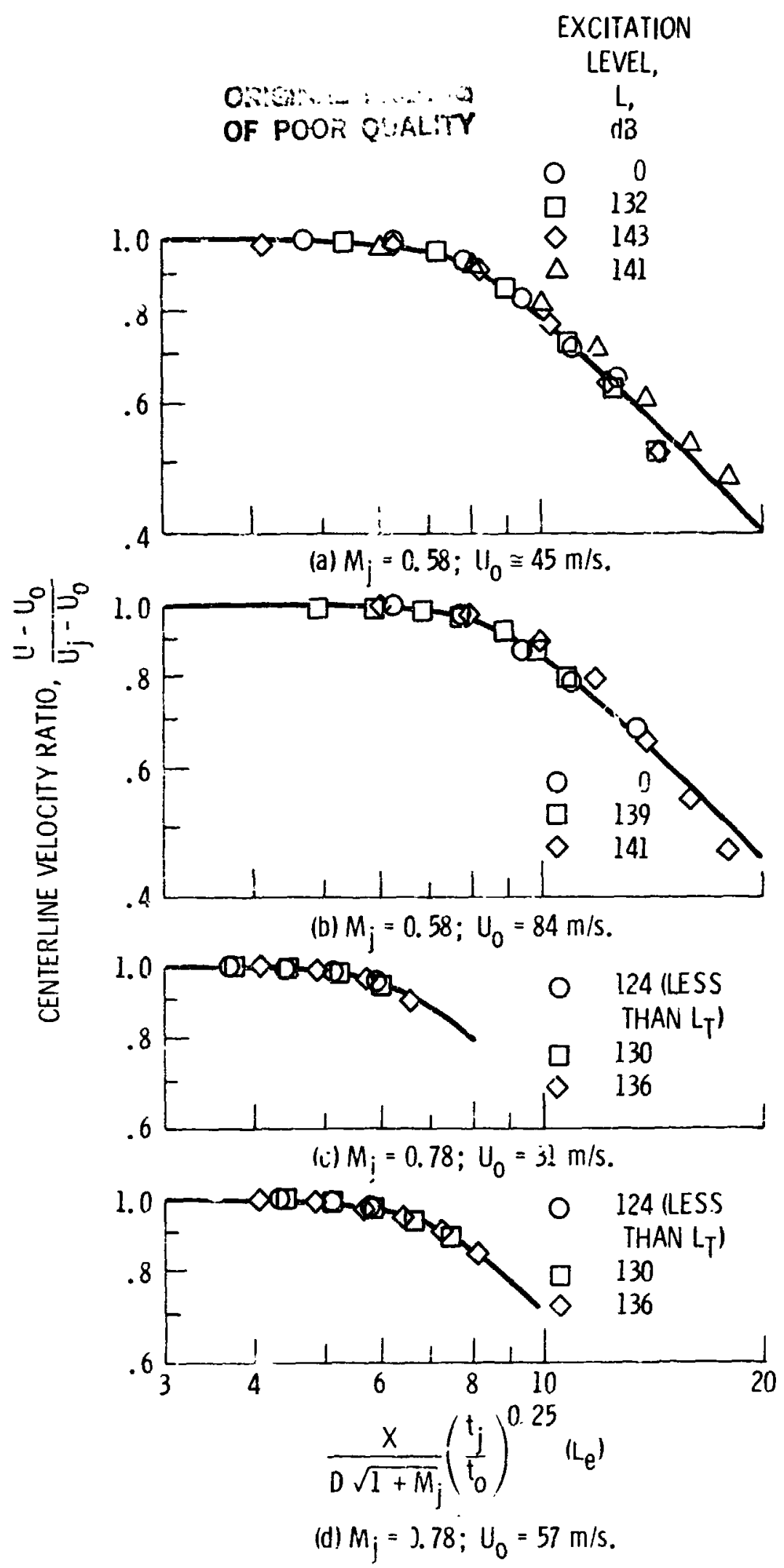

Figure 9. - Coirelation of centerline jet velocity decay for constant ilight conditions, with and without excitation. 
OF POOR QUALER

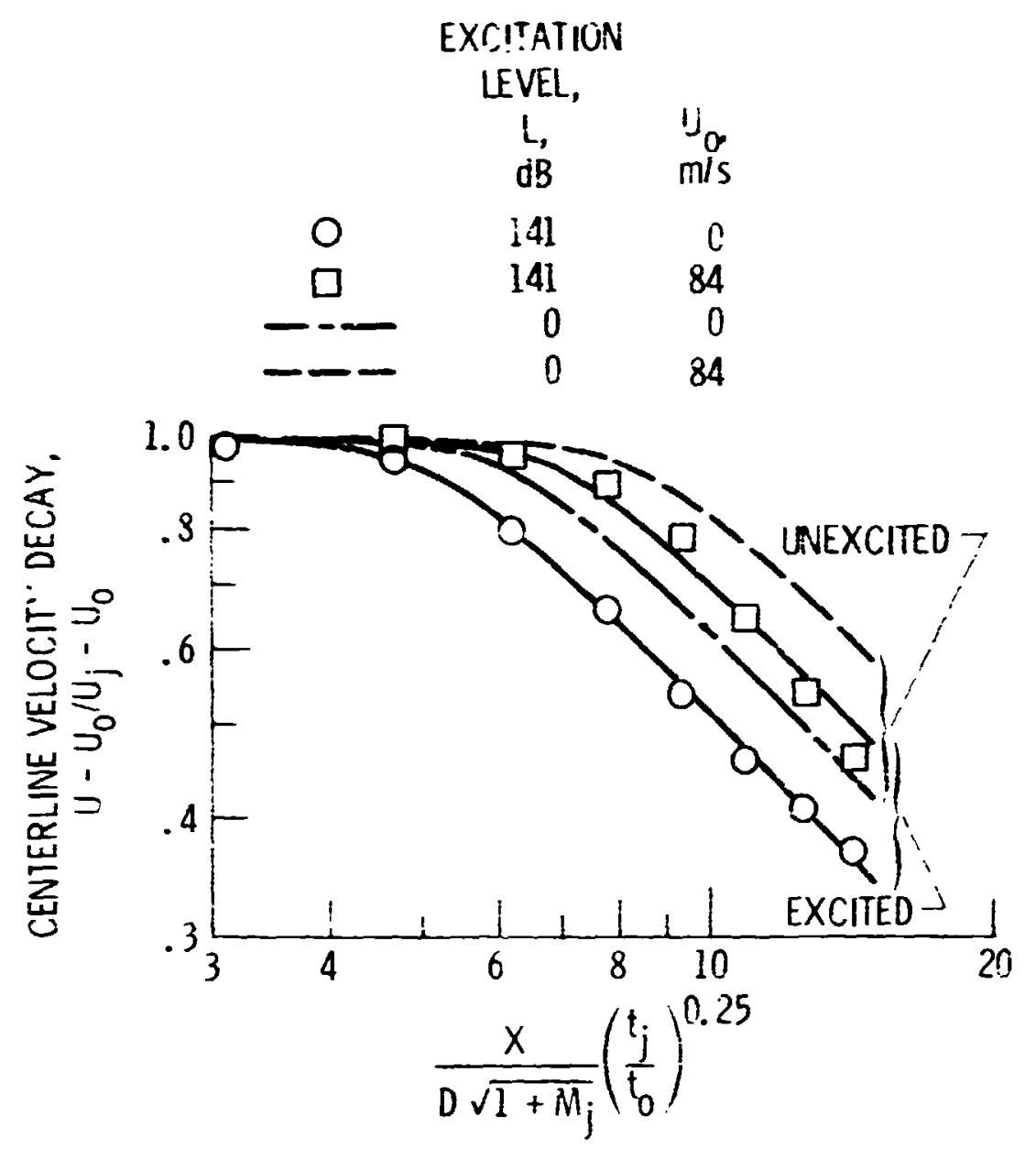

Figure 10. - Effect of flow excitation in centerlirie velocity decay with and without flight speed. $M_{j}=0.58$. 


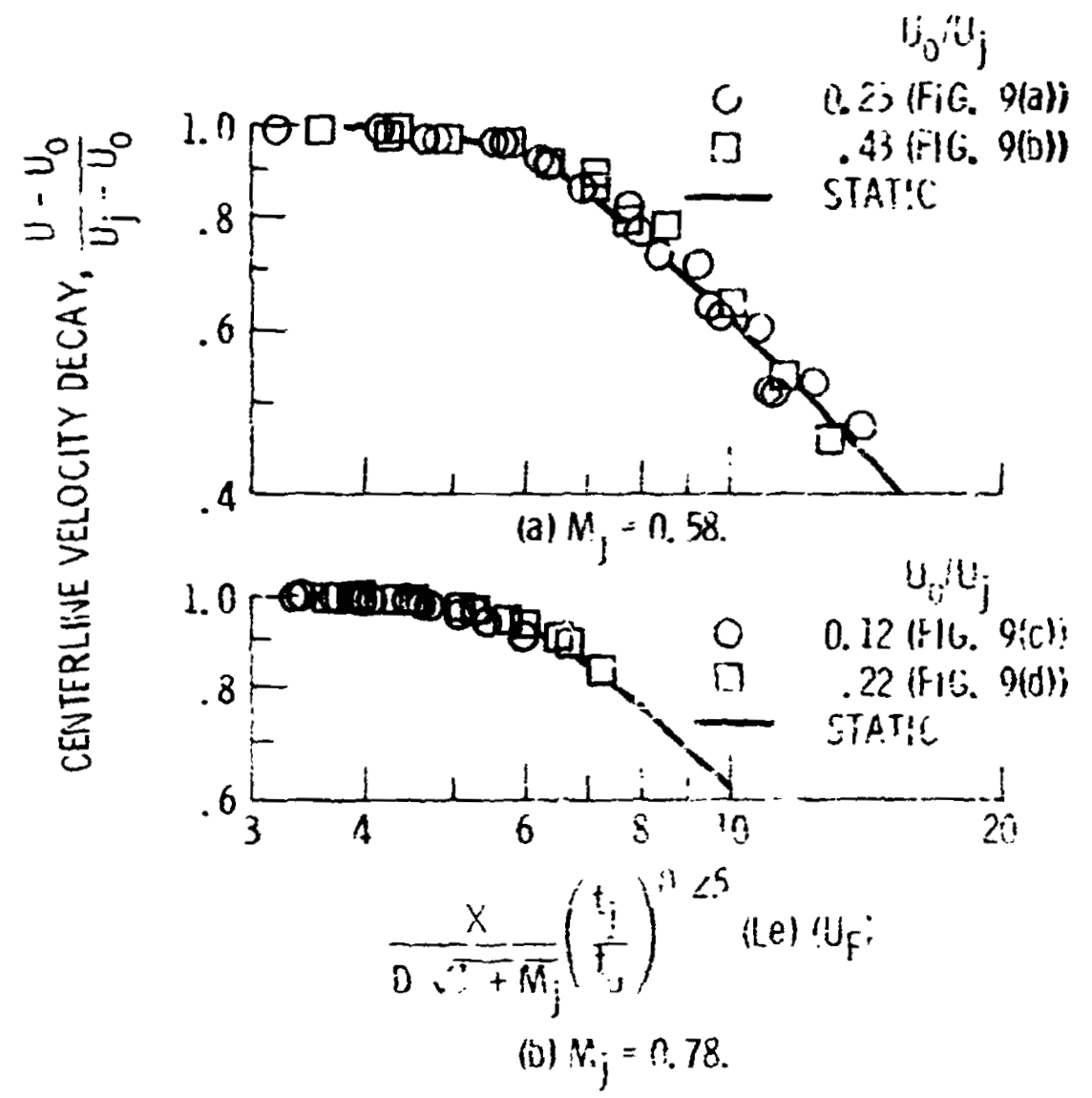

Figure 11. - Correlatio: of in-fijont cenierline velority decay itith excitation. 
ORIGINAL PAGE IS
OF POŨR QuALITY
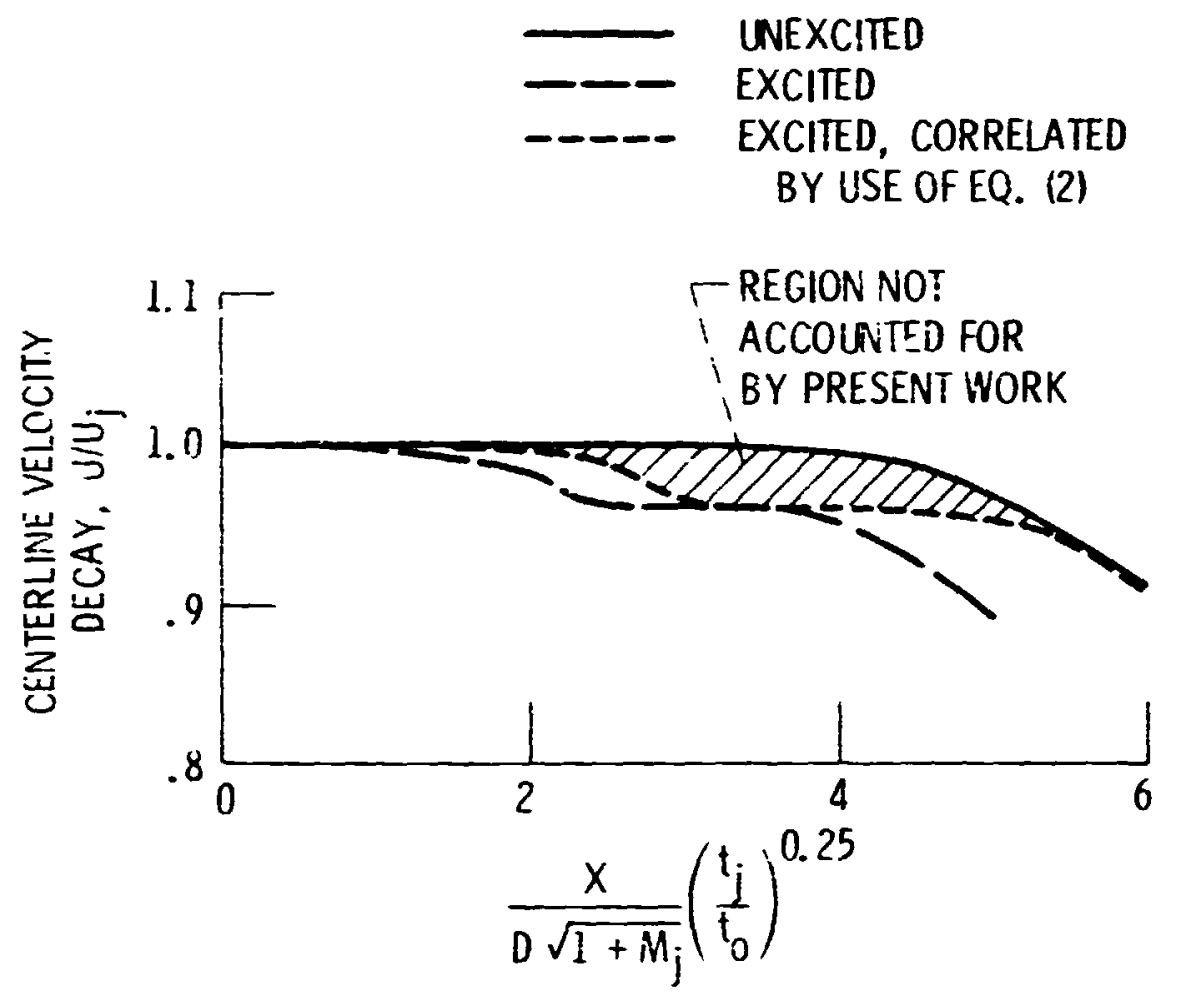

Figure 12. - Close-up of centerline jet velocity decay core region. Static conditions; $M_{j}=0.58$. 